

\section{Article Artículo Paper Presentació: \\ Cap a una guia \\ de formació sobre intervenció amb joves en contextos d'immigració}

\section{Carles Serra ${ }^{1}$}

¿Quines són les necessitats de formació dels professionals de l'acció social que treballen amb joves en contextos d'immigració? ¿I les de recerca? ¿A què hem de donar prioritat perquè tant la intervenció com la recerca tinguin sentit i atenguin el que és més necessari? ¿Podem preveure problemes que ara potser només són emergents -amb prou feines tenim indicis que ens permetin intuir-los- però en un futur proper seran cabdals? I qui diu l'acció, diu les polítiques: ¿Qui, com i en funció de què pot o ha de decidir quina és l'orientació adequada de les polítiques d'immigració (o de ciutadania?), d'acollida (o de convivència?), d'integració (o d'inclusió?), de diversitat (o d'igualtat?), d'interculturalitat (o d'antiracisme?)? ¿I qui les ha d'assumir: els serveis socials? els de joventut? els de cultura? els d'educació? els de seguretat? ¿O som agosarats $-i$ coherents- $i$ assumim el risc de dir que ha de ser una política transversal coneguda, assumida i compartida per totes les àrees -amb el risc que no n'hi hagi cap que s'encarregui d'impulsar-la, ni de vetllar

1. Universitat de Girona 
perquè el seu impuls sigui coherent $i$ estigui ben orientat i no hi hagi contradiccions o mancances gaire importants-?

¿I si algunes d'aquestes preguntes ja tenen resposta -explícita, raonada, aplicada i contrastada- i és només la ignorància i la imperícia d'uns investigadors que tot just comencen a desplaçar el focus d'atenció cap a un àmbit nou, el que fa que se les plantegin? Tant hi fa, de totes les qüestions, només l'ultima és sobrera. Millor encetar el treball amb bones preguntes que amb respostes imaginades, sense fonament o incoherents.

Aquest era el punt de partida en començar a treballar sobre les situacions i problemàtiques que fan front els joves immigrats: tots els dubtes i molt poques respostes -és el que passa quan les que hi ha a l'abast no convencen-, però amb voluntat d'afrontar reptes nous i de provar de dir coses que poguessin tenir alguna rellevància (aquella pretensió de l'antropologia o les ciències socials "aplicades" o, encara millor, "implicades"). Aquest número de Pedagogia i Treball Social. Revista de ciències socials aplicades presenta alguns resultats del treball realitzat des d'aleshores.

Sovint des de l'acadèmia es peca d'un excés d'autoreferencialitat (compareu, si no, les bibliografies dels articles redactats pels acadèmics i pels professionals de l'acció social que apareixen publicats en aquest número). Una autoreferencialitat que té dues conseqüències:

1. D'una banda que el debat acadèmic es pot allunyar de les necessitats més sentides o més immediates dels polítics, els professionals o les persones a qui s'adrecen les accions d'aquests.

2. D'una altra, que pot abocar els acadèmics a ignorar els coneixements que tant responsables polítics, com professionals, com la població diana, tenen i han generat sobre les realitats que viuen o en què treballen.

Si el primer punt és o no és un problema depèn dels interessos o les prioritats dels mateixos investigadors: la recerca bàsica (profundament teòrica, conceptual, allunyada de les necessitats immediates de la intervenció) té sentit per ella mateixa. És pràcticament impossible saber quina serà la utilitat del coneixement que generem (si és que n'arriba a tenir alguna), però això no resta legitimitat, ni mèrit, ni interès a la inversió de temps i esforç en àrees 
i qüestions que, d'entrada, semblen lluny de tenir cap utilitat "pràctica" o de ser rellevants per a cap debat que la societat tingui plantejat o hagi de posar damunt la taula (el xamanisme, l'art rupestre, els forats negres o l'origen de la sardana, per dir-ne alguns que a priori poden semblar més "recreatius" que rellevants, però que a la llarga han demostrat que les hores de reflexió que han merescut estaven més que justificades). El problema és quan l'investigador, l'acadèmic, vol fer aportacions a debats que els polítics, els professionals o la societat tenen plantejats, i ho fa des d'abstraccions, complexitats teòriques i debats que poc tenen a veure amb el que se'ls reclama. Si es volen fer aportacions als debats socials, cal conèixer els reptes, les necessitats i l'estat dels sabers amb què treballen tots els agents socials implicats. L'autoreferencialitat, aleshores, és un problema. Podem assistir a debats interminables sobre la interculturalitat, per exemple, davant d'auditoris al·lucinats que es demanen per què carai es dedica temps a discutir sobre això quan a ells el que els marca la vida és la llei d'estrangeria, les discriminacions en l'accés a l'habitatge o la mala relació amb els veïns o els companys d'aula; o a experts que quan els demanen que concretin com es pot traduir la seva proposta en accions concretes, no se'ls acudeix res més que proposar... la realització de tes interculturals.

La segona conseqüència és més greu, perquè genera una jerarquia de sabers del tot injustificada. El diàleg és difícil quan els que el practiquen ho fan des de posicions allunyades $\mathrm{i}$ tenen interessos, necessitats, prioritats, urgències i ritmes de treball diferents, $\mathrm{i}$ se'ls exigeixen coses diferents a l'hora de justificar la seva feina. I encara és més difícil quan es tendeix a reconèixer com a "saber", com a coneixement realment valuós i digne de ser tingut en compte, només el saber generat entre els iguals.

\section{La creació d'un grup de treball sobre joves i immigració}

Afortunadament cada vegada sorgeixen més iniciatives orientades a posar en valor els coneixements dels professionals i els de les persones a qui s'adrecen les polítiques i les accions (els ciutadans en general o les persones i collectius específicament afectats) ${ }^{2}$. Va ser a partir d'aquest reconeixement i de la voluntat de poder treballar amb la intenció de donar resposta a alguna necessitat real, que, d'acord amb alguns companys que des de fa anys treballen per a millorar la

2. Casademont, X., Planas, A., Serra, C. Soler, P. (2020). "Breaking down barriers: the co-construction of knowledge between practitioners and researchers”. [En procés d'edició]. 
resposta que la societat i les institucions donen als reptes que en general planteja la immigració, vam decidir organitzar i constituir un "grup de treball" ${ }^{3}$. El nom ha anat canviant, de Grup de treball sobre la intervenció amb joves en barris receptors d'immigració ha passat a Grup de treball sobre joves i immigració: el primer més precís, el segon més pràctic. El bo és el primer, perquè la intervenció consideràvem que era un bon punt de partida (identifiquem quins són els reptes, les problemàtiques que estem abordant, plantegem-nos en quina mesura estan ben definides i són les que realment pensem que cal abordar, i preguntem-nos si la manera d'abordar-les és la més correcta) i perquè l'objecte de reflexió no són "els joves immigrats" sinó allò que els envolta (d'aquí que parlem de joves -immigrats o no-i de barris o de contextos d'immigració ${ }^{4}$ ). Però l'economia mana: "Joves i immigració". "Joves" perquè la seva realitat és diferent de la dels seus pares, i encara són els adults els que atrauen més la nostra atenció. I quan l'han atret els joves ho han fet, massa vegades, en qualitat d'estudiants. Possiblement perquè l'escola uniformitza i ajuda a simplificar les coses, però la joventut, diversa com és, qui té capacitat d'atrapar-la? També uniformitza la immigració: pensem "un immigrant", i l'hem pensat home i adult, i amb un reptes comuns tan si és gambià, com ucraïnès, com d'Hondures; i pensem en la llengua, l'acollida, la interculturalitat... Però, els joves! És com obrir la caixa dels trons: nascuts aquí $i$ a fora, escolaritzats i sense escolaritzar, racialitzats i no racialitzats, amb dificultats d'inserció professional o amb carreres universitàries, màsters i doctorat, amb referents familiars al territori o sense, amb una xarxa social diversa o marcats per la ferida de l'estigma, el racisme i l'exclusió. A partir d'aquí, ¿¿qui és capaç de fer un diagnòstic dels joves tocats pels processos de la immigració? Però són el futur-més present cada vegada-i nosaltres badem: perquè són el que serem, o són el que som i no ens n’hem adonat encara.

Doncs els joves, i tots. Perquè qui diu qui és immigrat i qui no ho és? I qui diu que el problema és dels joves immigrats i no dels altres? ¿I qui diu que allò sobre el que hem de treballar són els joves -que són esquerps, maleducats, rebels; que no s'integren, que no s'adapten- i no la societat -esquerpa també, tancada, que ni integra ni està integrada, ni dona oportunitats-?

Els membres del Grup de Treball han anat canviant al llarg de tot el procés (que arrenca el febrer de 2017, s'entrebanca amb la repressió de l'estat contra la revolta catalana

3. Aquesta iniciativa formava part del projecte ProspecTaso (Prospectiva Transfronterera Sanitària i Social), que ha comptat amb el finançament del programa Interreg POCTEFA Ref: EFA019/15.

4. Per a organitzar aquest treball, la proposta de Carol Bacchi (2009) ha estat especialment útil. 
i s'atura amb els confinaments, a l'espera que les possibilitats de trobada presencial i les urgències de la crisi sanitària i social permetin la represa de les sessions de treball). Hi han passat una trentena de professionals, estabilitzant-se el grup en una quinzena de persones que assisteixen de manera regular a les trobades cada mes i mig ${ }^{5}$. Lobjectiu del Grup era conèixer i reflexionar sobre les situacions que s'estan abordant des de les entitats del tercer sector i les institucions en relació als joves que viuen en contextos d'immigració. Reflexionar sobre les problemàtiques i sobre les estratègies d'intervenció.

A banda de les presentacions i els debats interns del Grup, també es va anar convidant a altres professionals i a investigadors que han treballat sobre problemàtiques properes. És el cas de Martin Lundsteen $(2013,2017,2019)$ i de Nuria Riera, entre altres. Núria Riera va poder explicar de quina manera des del Consorci de Benestar Social del Ripollès s'ha abordat el trauma que va generar la participació de joves de Ripoll en l'atemptat del 17 d'agost de 2017.

A banda de les trobades regulars del Grup de Treball, es van organitzar dos seminaris de treball transfronterers, un a Tolosa i un altre a Perpinyà. El primer va permetre conèixer diferents serveis i dispositius adreçats als joves que viuen al que a Tolosa es qualifiquen com a "quartiers sensibles"-recursos culturals, serveis de suport comunitari, dispositius d'inserció professional i de suport educatiu, bàsicament. A Perpinyà el seminari ens va permetre contrastar discursos i metodologies desenvolupats al nord i al sud dels Pirineus.

A més d'aquestes trobades, a partir del treball del Grup es van organitzar tres trobades més: una Girona, amb professionals que fan intervenció directa amb joves immigrats;

5. Els integrants del Grup de Treball han estat: Ouafae Acharki (mediadora i dinamitzadora, Consell Comarcal Alt Empordà), Vicky Blanco (educadora, Espai Jove de Palafrugell, Coop. Suara), Eulàlia Bofill (cap progr. educació, Càritas Girona), Andreu Bover (cap d'àrea de Ciutadania i Immigració, Aj. Salt), Mònica Caldas (cap progr. suport jurídic, Càritas Girona), Pere Cortada (tècnic de la Secretaria d'Igualtat, migracions i ciutadania a Girona), Nia Farreras (tècnica d'acollida, Aj. Girona), Carolina Fontàs (tècnica d'acollida i diversitat, Aj. Sta. Coloma de Farners), Maite Irazola (tècnica de ciutadania, Aj. Anglès i Sant Hilari Sacalm), Neus Juanola (tècnica en polítiques migratòries, Consell Comarcal Alt Empordà), Marta Julián (educadora, Espai Jove de Palafrugell, Coop. Suara), Jordi López (educador social, Consorci d'Acció Social de la Garrotxa), Abdesselam Loukan (mediador i dinamitzador, Consell Comarcal Alt Empordà), Laura Masó (coord. Territorial de Joventut a Girona), Carme Noguera (coord. Servei d'immigració i diversitat, Aj. Figueres), Laura Prunell (tècnica de Ciutadania, Aj. Cassà de la Selva), Jordi Roura (tècnic de Joventut, Aj. Girona), Esther Salvachúa (responsable àrea educació, Fundació SER.GI), Carles Serra (antropòleg, Universitat de Girona), Cristina Sibina (educadora social, Salt), Julia Ventura (educadora social, Consell Comarcal Pla de l'Estany), entre altres. A més hem comptat amb el suport tècnic de Irene Mates, Marta Navarro i Sandra Borneis (tècniques de suport del projecte ProspecTsaso) i la collaboració de Slimane Touhami (professor i investigador del centre ERASME, Institut du Travail Social), entre altres. 
i dues més a Salt, totes dues amb joves que han viscut de prop la immigració (joves immigrats, refugiats, fills de famílies immigrades o joves autòctons que participen de moviments socials que incideixen en problemàtiques com el racisme o l'acollida de la població immigrada de països del Sud). Totes tres trobades es van organitzar amb una metodologia flexible, pensada perquè fossin els mateixos participants els que establissin quins eren els temes de discussió en funció de l'interès o la rellevància que consideressin que tenien ${ }^{6}$.

Al seminari amb els professionals que treballen en contacte directe amb els joves els grups de discussió que es van crear a proposta dels mateixos professionals van $\operatorname{ser}^{7}$ :

\section{Racisme i discriminacions}

2. Documentació, qüestions legals i accés al treball

3. Relacions amb les institucions i amb el sistema educatiu

4. La identitat i les dificultats per al reconeixement

5. Emocions i acompanyament

I al primer seminari amb els joves, els temes que es van plantejar van ser aquests:

1. Racisme (analitzant la qüestió des de nivells de reflexió molt diversos: des de l'exposició de casos viscuts, fins a l'anàlisi del racisme des de la perspectiva decolonial).

2. Gènere-feminisme-privilegis-interseccionalitat

3. Documentació, qüestions legals i accés al treball ${ }^{8}$

6. Cadascuna de les sessions la vam plantejar a partir d'una adaptació de la metodologia EdCamp (https://edcamp. educaciodema.cat) que els darrers anys a Catalunya ha estat promovent la Fundació Jaume Bofill. Aquest format permetia que fossin els mateixos participants els qui determinessin els temes que es discutirien i que s'organitzessin en grups de treball amb total llibertat a l'hora de conduir els temes, proposar-ne de nous i canviar de grup quan cadascun dels participants ho estimés convenient. Vam pensar que era una bona opció per tal de no imposar la nostra mirada sobre la temàtica objecte de discussió (els joves immigrats, els seus reptes, inquietuds i problemàtiques) i fer que fossin els mateixos participants els qui assenyalessin sobre què calia discutir i en quins termes.

7. Enumerem els temes perquè ens sembla significatiu quines són les qüestions a què els professionals donen rellevància $\mathrm{i}$ quines són les que els mateixos joves consideren rellevants. Podríem afegir: si en uns llistats i altres hi hagués grans discrepàncies ens hauríem de demanar per quin motiu n'hi ha, i si no n'hi ha gaires (com és el cas) possiblement la següent pregunta a fer-nos és si les "necessitats" sentides pels joves i les "atribuïdes" pels professionals es corresponen amb les prioritats que es fixen des de les institucions. En tot cas, cadascú pot fer aquest exercici i arribar a les conclusions que consideri pertinents.

8. Aquest grup va esdevenir gairebé un taller d'assessorament atès el perfil de les persones que van participar-hi. Tanmateix, aquest fet sembla prou significatiu de les necessitats i la desorientació que hi ha entorn a aquestes qüestions. 
4. Educació (des d'una perspectiva molt crítica amb la manera com s'han sentit tractats per les escoles i instituts per on han passat) ${ }^{9}$.

5. La gestió de la identitat (vinculant aquesta qüestió especialment amb les relacions familiars).

Al document de convocatòria del segon seminari amb joves, es recollien algunes de les idees que van expressar-se en el primer, com a qüestions que ells mateixos van plantejar i que van quedar obertes. Aquestes qüestions:

—És una trampa la "integració"?

— Com hem d'entendre i gestionar les discrepàncies que es generen entre pares/ mares i fills/filles?

- Com podem treballar contra la discriminació quan aquesta es produeix a través de les institucions? (de l'escola, per exemple, que se'n va parlar molt)

- Es tendeix a vincular les "persones immigrades" amb "problemes", podem fer res per canviar aquesta percepció?

- Per a molts dels nostres pares el dret a vot no era una prioritat. Però i per a nosaltres?

- I el mateix passa amb l'accés a l'administració, que per a treballar-hi cal tenir nacionalitat espanyola. Ens hi hem de conformar? ${ }^{10}$

I a partir d'aquí se'ls va plantejar la possibilitat de donar continuïtat a aquestes trobades o de constituir un grup de treball (de formació o de debat o de coordinació) amb joves amb interès per aquestes qüestions (que poden tenir-hi un interès personal o que estan treballant-hi des d'associacions o moviments diversos). Aquest podria ser una de les propostes de continuïtat del projecte ProspecTsaso en la seva nova edició.

9. Val a dir que a la sessió hi havia des de persones que han tingut un contacte molt breu amb el sistema educatiu català, fins a persones que l'han reconegut de cap a cap; i des de persones que han abandonat el sistema, fins a persones que han acabat a la universitat.

10. Aquestes qüestions es van plantejar en la primera trobada amb els joves. Nosaltres les vam posar damunt la taula en la segona trobada, perquè en la primera ocasió van donar joc a debats molt interessants i extensos. 


\section{El banc de projectes}

Finalment, en paral·lel al Grup de Treball (i amb els suport dels seus membres) es va encarregar a la Fundació Campus Arnau d'Escala la creació d'un Banc de projectes d'intervenció amb joves en contextos d'immigració. Es tractava d'identificar els projectes que s'han desenvolupat des del 2005 fins avui per a treballar amb joves que viuen en contextos d'immigració i incidir en les seves problemàtiques, necessitats i contextos en què viuen. L'abast territorial del Banc és tot Catalunya, si bé la recerca s'ha centrat de manera més exhaustiva en les comarques de Girona. Al Banc de projectes s'identifiquen les problemàtiques treballades i les metodologies emprades, s'hi recull la documentació generada i es faciliten dades de contacte. La intenció és que sigui un recurs per accedir a informació sobre projectes diversos, posar-los a l'abast dels professionals o les institucions que puguin estar-hi interessades i fomentar-ne la difusió i l'intercanvi. També volem que sigui una eina que permeti resseguir què i de quina manera es treballa, que permeti identificar en què s'ha anat incidint en cada moment i quines temàtiques no s'han treballat encara.

El Banc de projectes és un recurs obert. En dos sentits: es va penjar al web per a facilitar l'accés a tothom qui hi estigui interessat; i segueix en construcció: s'ha obert amb 53 projectes $^{11}$, però es demana que qui tingui notícia d'entitats, professionals o institucions que hagin desenvolupat alguna iniciativa (programa, projecte, acció, servei) que d'una manera o altra incideixi sobre els joves que viuen en contextos on la immigració és una dimensió significativa, ens facilitin el contacte a través del correu electrònic info@campusarnau.org a fi que ens hi puguem adreçar per ampliar aquest Banc i la informació pugui ser cada vegada més completa. Podeu accedir al Banc de projectes a través d'aquesta adreça: http://www.campusarnau.org/bancdeprojectes/.

\section{Cap a una guia de formació}

Veiem que la feina desenvolupada des del Grup de Treball, ha estat diversa i, en alguns moments, intensa. En aquest número de la revista de Pedagogia $i$ Treball Social aportem la darrera de les tasques desenvolupades. A l'inici del projecte es va proposar la creació d'una

11. De 111 projectes identificats, vam obtenir una informació completa de 53, que són els que s'han incorporat al Banc. 
Guia de Formació. El nom generava incomoditat. Primer perquè la mateixa lògica del Grup de Treball ja qüestiona d'arrel la idea que hi hagi ningú amb coneixements i capacitat per a decidir en què cal formar els professionals (diversos com són i diverses com són les temàtiques en què treballen) $i$ amb coneixement $i$ capacitat per a donar resposta a les necessitats de formació identificades (unes necessitats que són canviants, com diverses poden ser les possibilitats de donar-hi resposta).

La dinàmica del Grup de Treball ha estat més la d'obrir-se al diàleg. Per això inicialment ens va semblar que tant interessant podia ser parlar de propostes de formació temàtiques, com de metodologies. La dinàmica del Grup de Treball és comuna a la de diferents grups de treball que s'han constituït entorn a grups de recerca del Departament de Pedagogia i de l'Institut de Recerca Educativa de la Universitat de Girona, on hi conflueixen professionals i investigadors que treballen sobre una mateixa temàtica. En l'actualitat n'hi ha tres: el Grup de treball sobre joves i immigració, el Grup de treball en politiques de joventut i recerca acció i el Grup de treball sobre coneixement professional, formació i recerca en serveis socials $i$ treball social. En tots tres s'ha generat una dinàmica de treball similar, basada en la co-creació de coneixement i el diàleg entre acadèmics i professionals que s'obren -un i altres- a aprendre dels interessos, experteses, dificultats i punts de vista da que cadascun d'ells té en torn a una mateixa temàtica. Es tracta, senzillament, de no establir les diferències com a repte a superar, sinó com a factor d'enriquiment. Tal i com hem assenyalat a la primera nota d'aquesta presentació, hi ha un article en procés de publicació (Casademont et al.2020) que fonamenta aquesta opció de treball i posa en valor tot el que aporta.

Més enllà del model de formació, doncs, què presentem en aquest número de la revista de Pedagogia i Treball Social? Bàsicament articles que recullen reflexions o que intenten donar resposta a qüestions que han anat apareixen en els debats del Grup. De dos tipus: unes de caire metodològic i unes altres entorn a reptes i àmbits d'intervenció.

\section{Formació en aspectes metodològics $\mathrm{i}$ instrumentals}

Quan parlem de metodologies, fem referència a estratègies d'intervenció i maneres de plantejar i organitzar el treball amb joves sobre les quals considerem que cal insistir, perquè no es tenen prou presents, encara no estan suficientment reconegudes o encara xoquen 
amb resistències fruit de les inèrcies polítiques i institucionals. Aquestes qüestions metodològiques (estratègiques, de planificació i d’organització) són:

1. En primer lloc, la necessitat d'apostar per dispositius flexibles, que s'adaptin a les poblacions i als contextos socials canviants que cal atendre, més que no pas facin una oferta de serveis i activitats que intuïm que poden ser interessants. La primera opció requereix un contacte estret amb les comunitats amb què es treballa (que poden ser barris sencers o grups de joves), un contacte estret i continuat que només és possible a través de l'acompanyament socioeducatiu i el treball comunitari. Entorn a aquesta qüestió hi reflexionen els dos primers articles. "El Güell Espai Jove: l'acompanyament socioeducatiu al servei dels joves i de la comunitat" presenta un dispositiu de la ciutat de Girona que s'ha bastit en base a aquests principis. L'article següent, "L'educació popular", signat per Slimane Touhami, antropòleg de l'Institut de Treball Social del Centre Erasme, de Tolosa, aporta alguns referents teòrics a aquest plantejament.

Val a dir que més enllà de proposar i defensar una manera de plantejar la pedagogia social, l'educació social i el treball social, al final del primer article s'incideix en un aspecte que estava molt present en molts dels debats del Grup de Treball: "Volen que el Güell”, s'hi diu, “esdevingui proper i amb capacitat de detecció, anàlisi i articulació de respostes per a les situacions noves i les fragilitats dels adolescents i joves en front d'una realitat que constantment està canviant”. Capacitat de detecció, anàlisi i articulació de respostes! Prendre el pols a una realitat que canvia molt ràpidament i que, si badem, quan la reconeixem ja hem fet tard, encara fem més tard quan arribem a entendre-la, i quan comencem a intervenir-hi potser ja ha canviat. És possible que en l'educació popular, l'educació social, el treball comunitari i l'acompanyament socioeducatiu ben plantejats hi trobem algunes respostes o, com a mínim, bones eines que ens ajudin a millorar la nostra capacitat de detecció de reptes i problemàtiques emergents. Pensem-hi, valorem-les i concedim-los els espais que es mereixen.

2. Els dos articles següents també van junts. En aquest cas, l'article de Slimane Touhami sobre "Participació i coneixements de les persones a qui s'adrecen les polí- 
tiques" posa en valor els sabers d'aquells que massa vegades hem tendit a reduir al paper d'“usuaris". Cada vegada hi ha més propostes que defensen la necessitat d'escoltar les persones amb qui treballem i d'afavorir la seva participació en la definició de les polítiques, les activitats i els serveis. Touhami en fa la defensa a partir de l'experiència francesa i l'Íngrid Pujol explica com ho ha treballat al Kasal de Joves de Roquetes, que durant molt de temps va ser un referent pel que fa a participació dels joves en la presa de decisions, gestió i organització d'activitats en un centre d'aquestes característiques. Participació, ens diuen, és empoderament, educació i democràcia, tot plegat prou important com perquè ens decidim a impulsar-la.

3. Un repte a l'hora d'organitzar sessions per al Grup de Treball era identificar experiències interessants que fossin reproduibles en les poblacions on treballen molts dels membres del Grup. La tendència a treballar amb exemples de "bones pràctiques" de vegades topa amb aquesta dificultat: els contextos socials són molt diversos i els recursos amb què es compta per a impulsar-les (personals, socials, econòmics o d'infraestructures), també. L'article de Neus Juanola i Imma Quintana incideix en aquesta qüestió. Des de la seva experiència al Consell Comarcal de l'Alt Empordà poden reflexionar sobre el que implica treballar en i per a municipis rurals, poblacions petites o mitjanes que possiblement no disposen dels recursos d'una gran ciutat, però que alhora compten amb un teixit social que pot ser un actiu que jugui al nostre favor si sabem tenir-lo en compte i incorporar-lo als projectes.

4. L'altre extrem el trobem en els municipis grans o en els consorcis o les diputacions que treballen per a conjunts de municipis. En aquests casos, la disponibilitat pressupostària i de personal, fa que es tendeixi a generar àrees o serveis que treballin de manera especialitzada. I això comporta riscos quan del que es tracta és d'intervenir sobre realitats socials o problemàtiques que requereixen un abordatge transversal o, millor encara, integral. Xavier Casademont, hi reflexiona perquè les paraules no són fetitxes que fan efecte en ser pronunciades (l'abordatge integral i la transversalitat massa vegades xoca amb la rigidesa i les inèrcies institucionals), identifica les principals dificultats i presenta propostes per a superar-les. 
5. Però més enllà de principis teòrics i qüestions organitzatives i institucionals, també presentem algunes eines concretes que s'han demostrat especialment útils per a l'atenció i el suport socioeducatiu als joves. En primer lloc el treball sobre les "habilitats per a la vida" sobre el qual fa anys que s'incideix des de l'Àrea de promoció de la salut del Dipsalut. En parlem perquè és un enfocament alhora social i personal, que ha estat vàlid per a treballar aspectes relacionats amb la salut, però que està pensat també per a fer front a reptes vitals i socials de tot ordre. I perquè no és prou conegut encara, tot i que les propostes que fa van guanyant terreny progressivament. Incorporar-la com un eix del treball socioeducatiu amb els joves i adolescents pot ser especialment interessant.

I finalment, la mentoria, que també viu un moment feliç, tant a Catalunya com a Europa. Òscar Prieto i Jordi Feu, els responsables del Projecte Rossinyol, en parlen per a assenyalar de quina manera l'apoderament dels joves es pot desenvolupar a través de relacions d'acompanyament.

\section{Formació sobre àmbits i problemàtiques específiques}

Més enllà dels aspectes metodològics, però, bona part de les sessions del Grup de Treball es van dedicar a reflexionar i discutir sobre problemàtiques específiques. Aparentment sobre conceptes, però de fons el debat era sobre la millor manera de definir, acotar i abordar un determinat problema. Aquesta preocupació s'ha traduït en un bloc de tres articles:

1. El primer sobre la inclusió, el segon sobre el reconeixement i el tercer sobre la perspectiva antiracista. El primer situa el concepte "inclusió" i la idea que cal treballar per a generar una societat i unes institucions inclusives. Serveix com a introducció a un debat més complex com és el que s'ha generat entorn a la idea de "reconeixement". Aquest concepte ha estat objecte de controvèrsies entre filòsofs, sociòlegs, antropòlegs i politòlegs. El concepte en si i la centralitat que ha de tenir en la definició i l'orientació de les polítiques d'integració, d'immigració o de ciutadania. Els autors de l'article reconeixen l'interès i el valor del concepte i de les polítiques que s'han proposat d'impulsar-lo, si bé també insisteixen que aquest "reconeixement" no s'ha de llegir únicament ni principalment en clau identitària, 
com massa sovint s'ha fet. L'article vol ser una excusa per a obrir un debat i que tots plegats comencem a plantejar-nos quins són els dèficits de reconeixement de les polítiques i les dinàmiques socials amb què hem estat treballant fins ara, $i$ que comencem a pensar de quines maneres podem procedir a aquest reconeixement des dels espais de treball propis de l'àmbit social. Tot un repte.

El tercer article, dels mateixos autors, es planteja com ha de ser una "Formació antiracista per als professionals de l'acció social". On som i on hauríem d'arribar. I on hauríem d'arribar si entenem l'antiracisme com una perspectiva de treball amb pretensions de globalitat, integral i prou definida com perquè no la considerem "una pota més" de la perspectiva intercultural, sinó l'eix central de les polítiques d'igualtat, convivència i diversitat que hem de desenvolupar per a donar resposta als reptes que la nostra societat té plantejats. Un article, doncs, per al debat.

2. I com no podia ser d'altra manera, l'altra gran tema que ha estat objecte d'anàlisi i reflexió al si del Grup de Treball és el dels radicalismes violents. Sobre aquesta qüestió en parlen Slimane Touhami, que presenta la manera com s'han conceptualitzat i abordat a França, i la Núria Riera i l'Alícia Mesas, del Consorci de Benestar Social de Ripollès, que van haver d'entomar el repte de curar les ferides obertes pels atemptats de l'estiu del 2017 al mateix temps que intentaven entendre perquè uns joves ripollesos van acabar participant activament en aquells atemptats, sense que ningú pogués arribar ni tan sols a imaginar-s’ho.

La prevenció del radicalisme violent ha esdevingut, per a molts, una prioritat. Nosaltres diríem que tot el que s'aporta en aquest número de Pedagogia i Treball Social. Revista de ciències socials aplicades té de fet aquesta orientació, perquè som del parer que la millor manera de lluitar contra el radicalisme violent, a més de lluitar contra els que el promouen, rau a treballar per una societat més justa i cohesionada. Les habilitats per a la vida, l'acompanyament socioeducatiu, el reconeixement, la participació, l'antiracisme o la integralitat de les polítiques, entenem que són eines i perspectives de treball que ens ajuden a avançar en aquest sentit.

3. Finalment, la revista es tanca amb dos articles dedicat, el primer, al suport a les trajectòries educatives i formatives dels joves migrats des de l’àmbit social (el treball 
a desenvolupar des del sistema educatiu mateix ha estat extensament treballada i podria ser objecte de tot un altre monogràfic). El segon, aporta una mirada crítica sobre dispositius del sistema de protecció a la infancia i l'adolescència a Catalunya.

Podríem haver inclòs més temes i podríem haver apostat per un format més "didàctic" (un repertori de solucions i de recomanacions), però entenem que amb això no hauríem fet més que falsejar la realitat. Primer perquè de solucions facils i "receptes a administrar" no n'hi ha. No pot haver-n'hi en un àmbit tan dinàmic, variable i internament divers com aquest. I en segon lloc, però principalment, perquè sempre és més ric interessant compartir mirades, experiències, dubtes i coneixements. I reflexionar conjuntament, tal com hem anat fent aquests darrers mesos els membres del Grup de treball sobre joves $i$ immigració i com us convidem a fer amb la lectura d'aquests articles.

\section{Bibliografia}

Bacchi, C. (2009). Analysing Policy: What's the problem represented to be? Frenchs Forest: Pearson.

Casademont, X., Planas, A., Serra, C. Soler, P. (2020). “Breaking down barriers: the co-construction of knowledge between practitioners and researchers". [En procés d'edició].

Lundsteen, M. (2013). “La convivencia difícil: conflictos 'culturales’ y recursos públicos en Salt, Cataluña”. A Narotzky (ed.) Economias cotidianas, economías sociales, economías sostenibles. Barcelona: Icaria.

Lundsteen, M. (2017). Super-diversity and the social production of space in a small Catalan town. IRIS Working Paper Series, no 17.

Lundsteen, M. (2019). Challenging Narratives of 'Native Flight' in a Small Town. Reflections on Moral Economies and Space. GRITIM Working Paper Series, no 40. 
Xedagogia i Treball Social

Revista de Ciències Socials Aplicades

Edita: Universitat de Girona

Disseny i maquetació: info@clam.cat · 647427732

Dipòsit Legal: GI.904-2010

ISSN: 2013-9063 